\title{
Covid-19: Gilead withdraws orphan drug designation from potential treatment after criticism
}

\author{
Elisabeth Mahase
}

The BMJ

The US Food and Drug Administration (FDA) has withdrawn orphan drug designation from a potential covid-19 treatment, after criticism that treating covid-19 as a rare disease was "disingenuous."

Pharmaceutical company Gilead requested that the FDA withdraw the designation - which was set to give the company a longer exclusivity period (seven years instead of five) and significant tax incentives-just days after it was given. ${ }^{1}$

Remdesivir, which works to inhibit viral replication, is a drug currently being investigated as a potential treatment for covid-19 through several clinical trials.

Orphan status is a mechanism designed to promote the development of drugs for rare diseases, where there is only a small number of people (fewer than 200000 people in the US) that could be treated.

Assistant director of the programme on regulation, therapeutics, and law, Ameet Sarpatwari, from Harvard Medical School, said, "The Orphan Drug Act was intended to spur the development of drugs for which there was no reasonable expectation of generating a profit, which is difficult to fathom in the case of a treatment for a growing pandemic."

Meanwhile, Tahir Amin, cofounder and co-executive director of I-MAK - a US based group that campaigns for increased access to affordable drugs- told The BMJ that "to call covid-19 a rare disease is disingenuous."

He said, "Gilead's decision to rescind its request for orphan drug designation was the right thing to do. But it should never have happened in the first place. Covid-19 is endemic and will now live in our ecosystem, which is why vaccines are being developed to ensure people are inoculated against it to prevent further outbreaks. Every person will likely want or need to get a vaccine when it becomes available.

"If approved, Gilead's remdesivir will also likely become a first line treatment for future flu seasons. So, to say this is a rare disease is to ignore what the future looks like. This whole episode raises a number of questions about Gilead's intentions and the FDA's judgment that makes it look like a captured institution."

Amin added that although the orphan drug designation had been removed, Gilead will still get five year new molecular entity exclusivity, "not to mention the patent exclusivities they have that currently run till at least 2038."

"It will still have a monopoly as it stands today. Which raises the next question of what they will do with it in this pandemic situation."

A spokesperson for the FDA said, "We received and processed a request from Gilead to withdraw orphan drug designation for remdesivir for the treatment of covid-19."

1 US Food and Drug Administration. Search orphan drug designations and approvals. Remdesivir. www.accessdata.fda.gov/scripts/opdlisting/oopd/detailedlndex.cfm? cfgridkey $=739020$.

Published by the BMJ Publishing Group Limited. For permission to use (where not already granted under a licence) please go to http://group.bmj.com/group/rights-licensing/ permissions 